\title{
Galvanic Interaction between Chalcopyrite and Pyrite with Low Alloy and High Carbon Chromium Steel Ball
}

\author{
Asghar Azizi, ${ }^{1}$ Seid Ziaoddin Shafaei, ${ }^{2}$ Mohammad Noaparast, ${ }^{2}$ \\ and Mohammad Karamoozian ${ }^{1}$ \\ ${ }^{1}$ Department of Mining, Petroleum and Geophysics, Shahrood University of Technology, Shahrood, Iran \\ ${ }^{2}$ School of Mining Engineering, College of Engineering, University of Tehran, Iran
}

Correspondence should be addressed to Asghar Azizi; azizi.asghar22@yahoo.com

Received 12 May 2013; Revised 17 July 2013; Accepted 17 July 2013

Academic Editor: Svetlana Ibric

Copyright (C) 2013 Asghar Azizi et al. This is an open access article distributed under the Creative Commons Attribution License, which permits unrestricted use, distribution, and reproduction in any medium, provided the original work is properly cited.

\begin{abstract}
This study was aimed to investigate the galvanic interaction between pyrite and chalcopyrite with two types of grinding media (low alloy and high carbon chromium steel ball) in grinding of a porphyry copper sulphide ore. Results indicated that injection of different gases into mill altered the oxidation-reduction environment during grinding. High carbon chromium steel ball under nitrogen gas has the lowest galvanic current, and low alloy steel ball under oxygen gas had the highest galvanic current. Also, results showed that the media is anodic relative to pyrite and chalcopyrite, and therefore pyrite or chalcopyrite with a higher rest potential acted as the cathode, whilst the grinding media with a lower rest potential acted as the anode, when they are electrochemically contacted. It was also found that low alloy steel under oxygen produced the highest amount of EDTA extractable iron in the slurry, whilst high carbon chromium steel under nitrogen atmosphere led to the lowest amount.
\end{abstract}

\section{Introduction}

The key to a successful separation in mineral processing is the preparation of particles with adequate liberation under the correct pulp chemical conditions [1]. Wet milling in ball mills followed by flotation is the general practice employed in the beneficiation of copper sulphide ores in which the major minerals of commercial significance typically are chalcopyrite $\left(\mathrm{CuFeS}_{2}\right)$, bornite $\left(\mathrm{Cu}_{5} \mathrm{FeS}_{4}\right)$, covellite $(\mathrm{CuS})$, and chalcocite $\left(\mathrm{Cu}_{2} \mathrm{~S}\right)[2]$.

It has been widely accepted that the grinding environment of sulfide minerals such as pyrite, arsenopyrite, chalcopyrite, galena, pyrrhotite, and sphalerite has a pronounced effect on the recovery and selectivity of sulphide minerals [3$10]$.

Galvanic interaction is one of the most important electrochemical factors, which governs the dissolution rate of sulphide minerals in hydrometallurgical systems [11]. It may occur in many minerals processing systems, flotation [1214], leaching of sulfide [15-17], and particularly wet grinding
$[18,19]$. Most sulfides are at best semiconductors. Therefore, during grinding due to sulphide mineral electrical conductivity a contact between mineral in ore and grinding media occurs which results in a galvanic couple between the media and the sulphide mineral. This increases dissolution of ferrous ions from grinding media, which are usually precipitated in the form of iron oxy-hydroxides on the surfaces of the sulphide minerals [20-22].

The extent of galvanic interaction between mineral and grinding media is dependent on the media type, minerals mineralogy, rest potential (open circuit potential) differences between sulphide minerals and grinding media, polarization behavior of the materials, comparative geometric ratio of the sulphide mineral to the medium in the couple, and grinding environment such as $\mathrm{pH}$, percent solid, viscosity, Eh, gas purging (air, $\mathrm{O}_{2}$ and $\mathrm{N}_{2}$ ), temperature, rheological properties, and water chemistry (i.e., anions; $\mathrm{Cl}^{-}, \mathrm{SO}_{4}^{-2}$; cations; $\left.\mathrm{Ca}^{+2}, \mathrm{Mg}^{+2}, \mathrm{Fe}^{+2}, \mathrm{Fe}^{+3}\right)[9-23]$.

A vast number of studies were carried out in investigating the electrochemical interactions between grinding 
media and sulphide minerals $[13,14,24,25]$. Generally, these studies indicate that most sulphide minerals are nobler than the grinding media used during grinding; therefore, a galvanic couple between the media and the sulphide mineral(s) exists, which increases the corrosion rate of the grinding media. In addition, these studies show that galvanic interaction between media and mineral not only promotes the corrosion rate of steel grinding media but also has a deleterious influence on the floatability of the ground sulphide minerals. Although extensive studies were carried out on the electrochemical interactions between grinding media and minerals in grinding of sulphide minerals and/or ores, but these investigations were not reported in grinding of porphyry copper sulphide ore. Pyrite and chalcopyrite, the most common and exploitable sulphide minerals, usually occur together and in contact with each other. Therefore, this paper was aimed to investigate the effect of galvanic interaction among chalcopyrite and pyrite with grinding media in grinding the Sarcheshmeh copper ore. In this study, influence of two factors including media type and dissolved oxygen were investigated in galvanic interaction between minerals (chalcopyrite and pyrite) and media.

The Sarcheshmeh copper ore is a major porphyry copper deposit, which is located in Kerman Province in the southeastern part of Iran. The Sarcheshmeh copper mine is the largest copper producer in Iran, and one of the major producers in the world market. In the concentrator plant, after three stages of crushing, the ore feeds to ball mills in a closed circuit with cyclones to produce $70 \%$ of the product finer than $75 \mu \mathrm{m}$ [26].

\section{Experimental}

2.1. Materials and Reagents. The Sarcheshmeh copper ore samples were obtained from the input feed to ball mills. Samples were crushed in a jaw crusher and then screened to collect the $+0.25-2 \mathrm{~mm}$ particle size fraction. Samples were then homogenized and sealed in polyethylene bags. Representative samples were chemically analyzed which their chemical compositions listed in Table 1.

In order to construct electrodes, samples of pure pyrite and chalcopyrite were collected from the Meiduck copper mine in the Babak city in Kerman Province of Iran and the Ghaleh Zari mine in Nehbandan city in south Khorasan Province of Iran, respectively. These samples were chemically analyzed. It is specified that pure pyrite and chalcopyrite minerals have $99.3 \%$ and $97.44 \%$ pyrite and chalcopyrite, respectively.

Two types of steel ball were applied as grinding media, which their chemical compositions are presented in Table 2. In this research, samples were ground with $8 \mathrm{~kg}$ ball in mixing of $0.5,0.75$, and 1 inch in diameter.

For preparing minerals and medium electrodes, medium and mineral samples were cut into a size of $7 \times 7 \mathrm{~mm}$ to fill in a Teflon tube. Then, a copper wire was connected to the back of the medium with electrically conductive silver epoxy. After that, the sample was mounted in a Teflon tube with the working surface exposed, and the central part of
TABLE 1: Chemical composition of the Sarcheshmeh ore sample (Wt $\%)$.

\begin{tabular}{lcccccc}
\hline \multirow{2}{*}{ Particle range } & \multicolumn{5}{c}{ Chemical compositions (Weight, \%) } \\
& $\mathrm{Cu}$ & $\mathrm{Fe}$ & $\mathrm{Mo}$ & $\mathrm{S}$ & $\mathrm{SiO}_{2}$ & $\mathrm{Al}_{2} \mathrm{O}_{3}$ \\
\hline 0.25 to 2 millimeters & 0.74 & 4.34 & 0.032 & 3.05 & 55.07 & 14.35 \\
\hline
\end{tabular}

TABLE 2: Chemical compositions of the grinding media.

\begin{tabular}{lccccccccc}
\hline \multirow{2}{*}{ Ball type } & \multicolumn{8}{c}{ Chemical compositions (Weight, \%) } \\
& $\mathrm{C}$ & $\mathrm{Si}$ & $\mathrm{S}$ & $\mathrm{P}$ & $\mathrm{Mn}$ & $\mathrm{Cr}$ & $\mathrm{Mo}$ & $\mathrm{Cu}$ \\
\hline $\begin{array}{l}\text { High carbon } \\
\text { chrome steel }\end{array}$ & 2.28 & 0.698 & 0.049 & 0 & 1 & 13.25 & 0.177 & 0.044 \\
$\begin{array}{l}\text { Low alloy } \\
\text { steel }\end{array}$ & 0.249 & 0.173 & 0.024 & 0.018 & 0.586 & 0.019 & 0.002 & 0.012 \\
\hline
\end{tabular}

the tube was sealed with nonconductive epoxy resin. The electrodes surface was gently polished with 500 grit silicon carbide paper prior to each test and cleaned with acetone and double distilled water. After each experiment, the used medium electrodes were repolished and then reused.

2.2. Grinding. The prepared representative samples ( $365 \mathrm{~g})$ were ground in a specialized ball mill with $8 \mathrm{~kg}$ balls in $\mathrm{pH}$, $7-7.5$, solid percentage, $35 \%$, and rotation speed, $75 \mathrm{rpm}$ for 12.5 minutes so that $70 \%$ of particles were finer than $75 \mu \mathrm{m}$ in diameter. This specialized grinding system was designed in R\&D of the Sarcheshmeh copper Mine. Ball mill was constructed using a stainless steel pipe with diameter of $21 \mathrm{~cm}$ and length of $30 \mathrm{~cm}$ with a wall thickness of $0.7 \mathrm{~cm}$. In order to study the electrochemistry of inside the mill, that is, to measure the slurry chemical conditions, polarization curves of balls, and minerals and their electrochemical interactions, an electrochemical apparatus associated with gas purging system was also linked to the mill. Schematic representation of specially designed grinding system illustrated in Figure 1.

The setup of experiments included a specialized ball mill, electrochemical tools, including, potentiostat/galvanostat coupled with a personal computer for data acquisition and potential control accompanied by a three-electrode system, the gas purging system, and meters for monitoring chemical conditions (Eh, $\mathrm{pH}$, and $\mathrm{DO}$ ).

Polarization curves of balls and minerals were determined using the computerized potentiostat/galvanostat (SAMA500 Electrochemical Analysis System, SAMA research center, Iran) and three-electrode system by Tafel extrapolation method and technique of linear sweep voltammetry (LSV).

The three-electrode system was comprised of an $\mathrm{Ag} / \mathrm{AgCl}$ (3.0 M KCl) electrode as a reference electrode, $\mathrm{Pt}$ wire as the counter electrode, and grinding media electrode as working electrode. All potentials were measured and reported versus the $\mathrm{Ag} / \mathrm{AgCl}(3.0 \mathrm{M} \mathrm{KCl})$ reference electrode $(+210 \mathrm{mV}$ versus $\mathrm{SHE}$ ). All polarization experiments were also carried out with a sweep rate of $50 \mathrm{mV} / \mathrm{s}$.

Moreover, in experiments, different gases (nitrogen, air, or oxygen) were continuously injected at the rate of $6 \mathrm{~L} / \mathrm{min}$ into the mill to change the oxidation conditions. The pulp was 


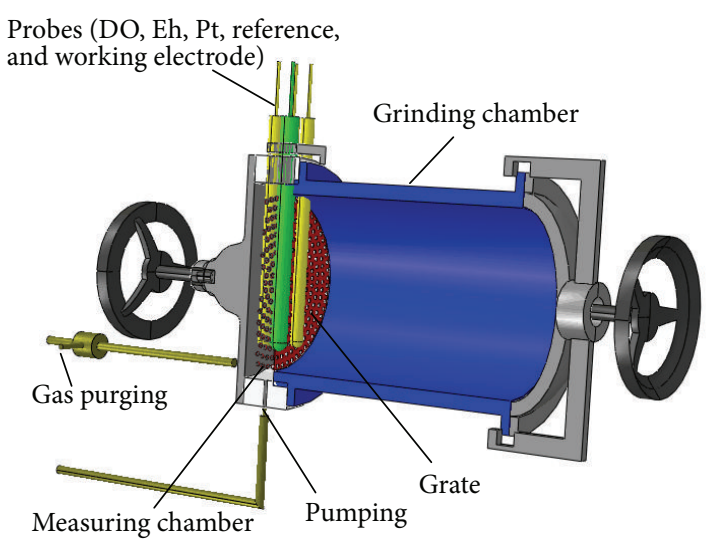

FIGURE 1: Schematic plan of specially designed ball mill.

also pumped out of the mill and mixed with the gases and then returned into the mill.

2.3. EDTA Extraction Technique. An EDTA (ethylene diamine-tetra acetic acid disodium) extraction technique has been widely used to determine the magnitude of oxidized iron species in the slurry [27]. Thus, EDTA extraction technique was carried out to determine the amount of oxidized iron species from minerals and/or grinding media on ball mill discharge as follows [27-29].

A 3 percent by weight solution of ethylene diamine-tetra acetic acid disodium salt was made up, and solution $\mathrm{pH}$ was adjusted to 7.5 sodium hydroxide. $250 \mathrm{~mL}$ of the EDTA solution was placed into a beaker and stirred using a magnetic stirrer. A $25 \mathrm{~mL}$ sample of the pulp was collected from mill discharge. Samples were weighted to determine the mass of pulp. The pulp was injected into the EDTA solution and then stirred for 5 minutes. At the end of the 5 minutes extraction time, the sample was filtered through a 0.22 micron Millipore filter paper using a vacuum filter. The filtrate was analyzed using atomic absorption spectroscopy (AAS). The solid from bulk sample from which have collected the $25 \mathrm{~mL}$ of pulp was assayed. Finally, the percent EDTA extractable iron was determined by dividing the mass of iron in the solution by the total mass of iron in the solids.

The EDTA extractable Fe percentage follows the methodology developed by Rumball and Richmond (1996) [27].

\section{Results and Discussion}

Potentiodynamic polarization is a direct current technique that gives fundamental information from, the corrosion rate, behavior of activity, passivity, and susceptibility to corrosion of the material. Also, polarization diagrams can be suitable to study galvanic interaction between minerals and grinding media. In the measurement, a potentiostat/galvanostat is used to control the driving force for the electrochemical reactions taking place on the working electrode (mineral or medium). Polarization curves of medium (low alloy and high carbon chromium steel balls), pyrite, and chalcopyrite electrodes were obtained using described electrochemical equipments. Results of potentiodynamic polarization studies for pyrite, chalcopyrite, and low alloy and high carbon chromium steel balls under different aeration conditions at a scanning rate of $50 \mathrm{mV} / \mathrm{sec}$ are illustrated in Figures 2 and 3. According to the results of Figures 2 and 3, the following observations can be obtained.

Figure 2 indicates polarization curves of low alloy steel ball, pyrite, and chalcopyrite under different aeration conditions and without aeration during grinding of the Sarcheshmeh copper ore with low alloy steel ball. Figure 2(a) exhibits that the cathodic polarization curves were extended from $-990 \mathrm{mV}$ to $-585,-377$, and $-239 \mathrm{mV}$ for medium, chalcopyrite, and pyrite, respectively, whereas anodic polarization of medium, chalcopyrite, and pyrite were extended, respectively, from $-585,-377$, and $-239 \mathrm{mV}$ to $+0.290 \mathrm{mV}$.

In Figure 2(a), the activity, passivity, and transpassivity regions can be clearly distinguished both for chalcopyrite and for pyrite. In the case of chalcopyrite, a passivation behavior around $-175 \mathrm{mV}$, and a transpassivation behavior was observed around $+180 \mathrm{mV}$ whereas for pyrite, passivation, and transpassivation behavior was seen around -63 and $199 \mathrm{mV}$, respectively. It was also observed active-passivetranspassive behavior for low alloy steel ball.

Figure 2(b) indicates that starting of passivity and transpassivity regions for low steel and chalcopyrite are attained 49 and $125 \mathrm{mV}$ and 218 and $257 \mathrm{mV}$ in air purging conditions, respectively, whilst no passive phenomenon is found for pyrite.

As can be observed in Figures 2(c) and 2(d), all of the curves follow a typical form of active-passive-transpassive anodic behavior.

Figure 3 indicates polarization curves of high carbon chrome steel ball, pyrite, and chalcopyrite under different aeration conditions and without aeration during grinding of the Sarcheshmeh copper ore. All of polarization curves for pyrite and chalcopyrite exhibit passivation behaviour; however, they differ in nature of transition from active to passive state. The polarization plots for medium show a small passivating region, which may be due to the iron hydroxide species, which passivates the steel ball surface and prevents further oxidation. The magnitude of passivity region under nitrogen atmosphere is the greater than other conditions in all of curves.

As seen in Figure 3, the current reach a limiting value around a potential of $-900 \mathrm{mV}$ for pyrite and chalcopyrite and $-940 \mathrm{mV}$ for high carbon chrome steel during cathodic polarization under nitrogen atmosphere (Figure 3(a)). Under air atmosphere, limiting current values attain around a potential of $-910 \mathrm{mV}$ for pyrite and chalcopyrite and $-860 \mathrm{mV}$ for high carbon chrome steel during cathodic polarization in air purging (Figure 3(b)). Limiting current value reach to a potential of -745 and $-930 \mathrm{mV}$ for minerals (pyrite and chalcopyrite) and high carbon chrome steel ball in $\mathrm{O}_{2}$ purging, respectively, whereas is achieved value around a potential of $-920 \mathrm{mV}$ for both minerals and medium without aeration conditions (Figures 3(c) and 3(d)). Limiting current value is not observed for pyrite and chalcopyrite in the anodic polarization while for the grinding media, limiting current value is attained at potentials above $+160 \mathrm{mV}$ in all of curves. 


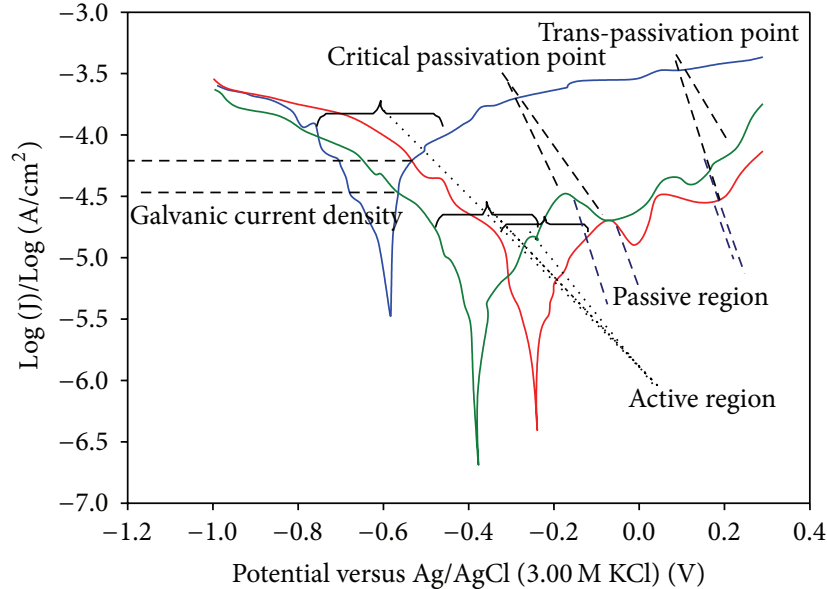

(a)

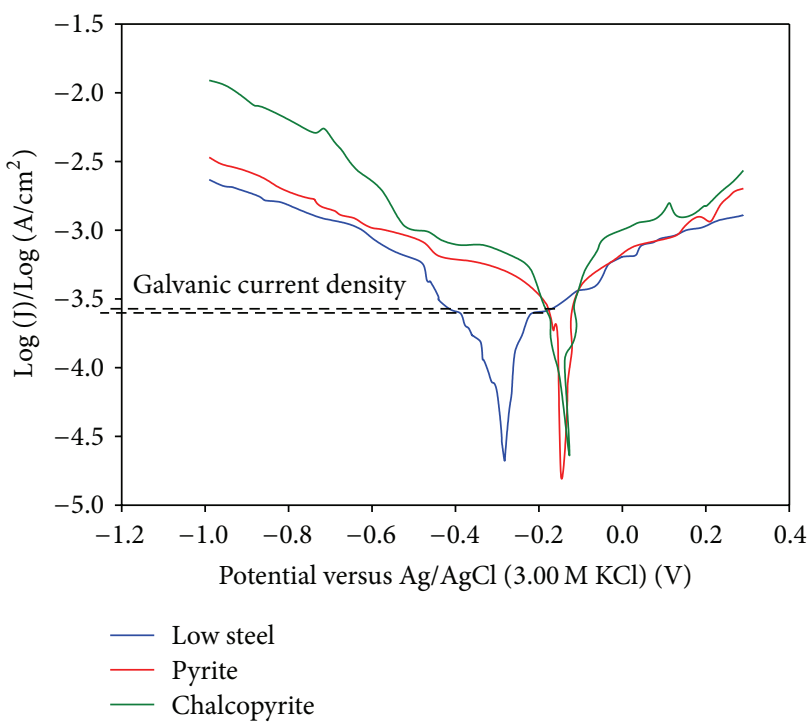

(c)

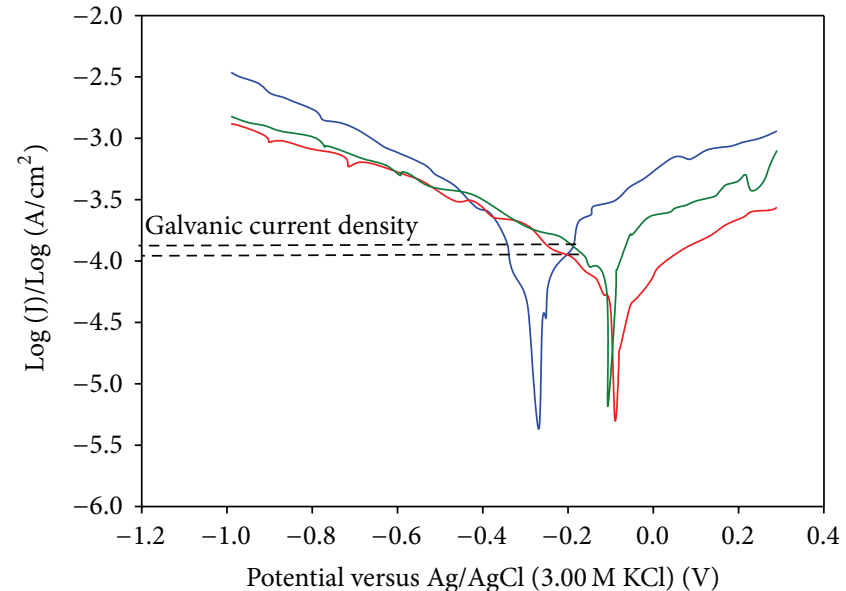

(b)

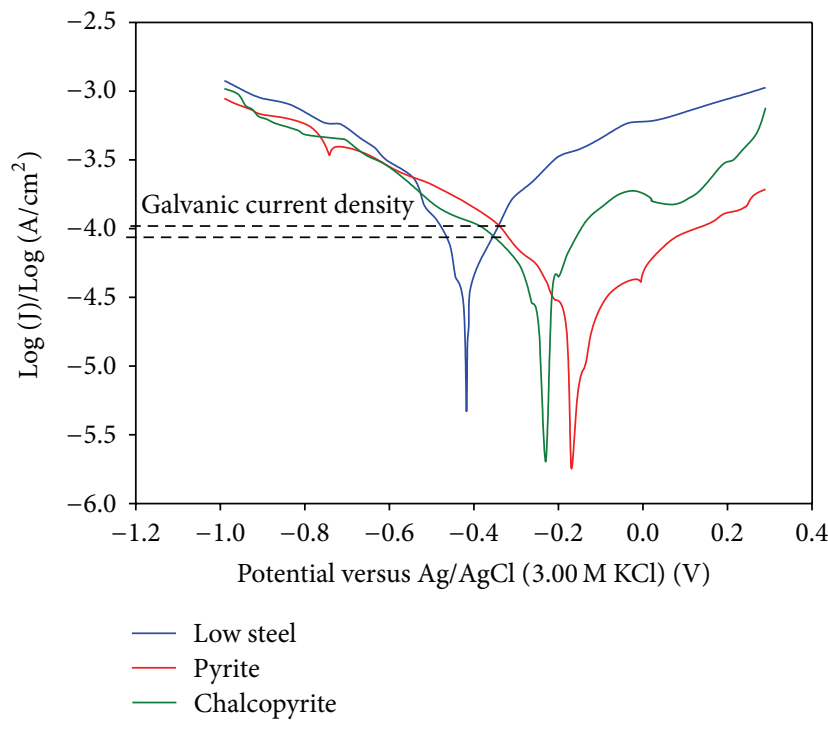

(d)

FIGURE 2: Potentiodynamic polarization sweep curves of grinding medium, pyrite, and chalcopyrite during grinding of ore with low alloy steel ball under nitrogen (a), air (b), and oxygen atmosphere (c), and without aeration (d) at a sweep rate of $50 \mathrm{mV} / \mathrm{s}$.

In addition, Figures 2 and 3 exhibit a method of how to calculate the galvanic current from the polarization curves of the minerals and medium. Current in the polarization curves represents rate of all electrons exchange reactions at the surface of the electrodes. Table 3 presents the steady-state combination potentials and the galvanic current densities of pyrite and chalcopyrite with low alloy and high carbon chromium steel ball, measured in mill by using polarization curves, exposed to the different gases (nitrogen, air and oxygen) and at $\mathrm{pH}$ of 7-7.5, during grinding of the Sarcheshmeh copper sulphide ore.

As can be considered in Table 3, different aeration conditions alter the oxidation-reduction environment during grinding. Oxygen in the grinding system produces the highest galvanic current in the medium-mineral (pyrite and/or chalcopyrite) couple during grinding, whilst nitrogenation resulted in the lowest galvanic current. As seen high carbon chromium steel ball under nitrogen gas has the lowest galvanic current for mineral-grinding media system and low alloy steel ball under oxygenation has the highest current. Therefore, the galvanic interaction between the grinding media and sulphide mineral was affected by type of media grinding and the injected gas (nitrogen, air and oxygen) type into mill during grinding.

Moreover, the derived results from Figures 2 and 3 and Table 3 show that the grinding media is anodic relative to the all sulphide minerals (pyrite and chalcopyrite), and the electrons flow from the media to the minerals. Thus, pyrite or chalcopyrite with a higher rest potential (open circuit potential, when net current is equal to zero) would act as the cathode, whilst the grinding media with a lower rest potential would act as the anode, when they are electrochemically 


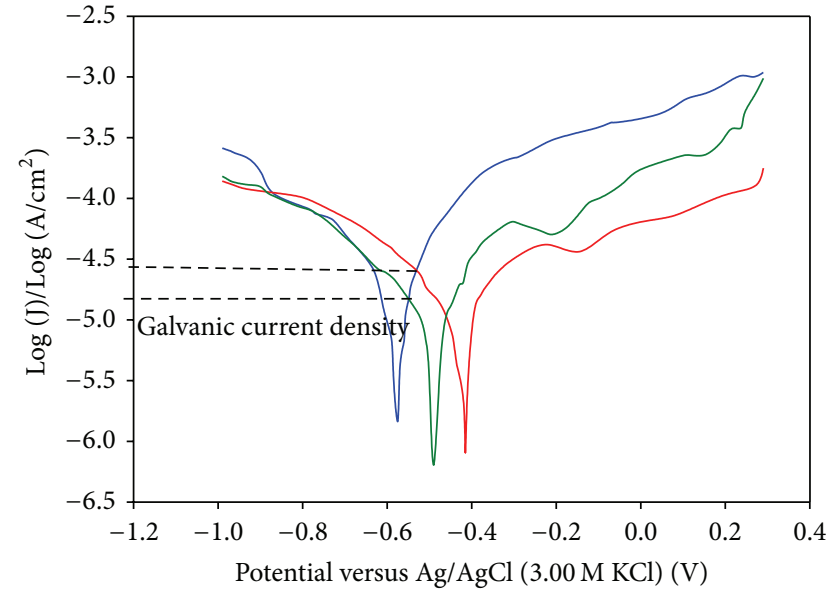

(a)

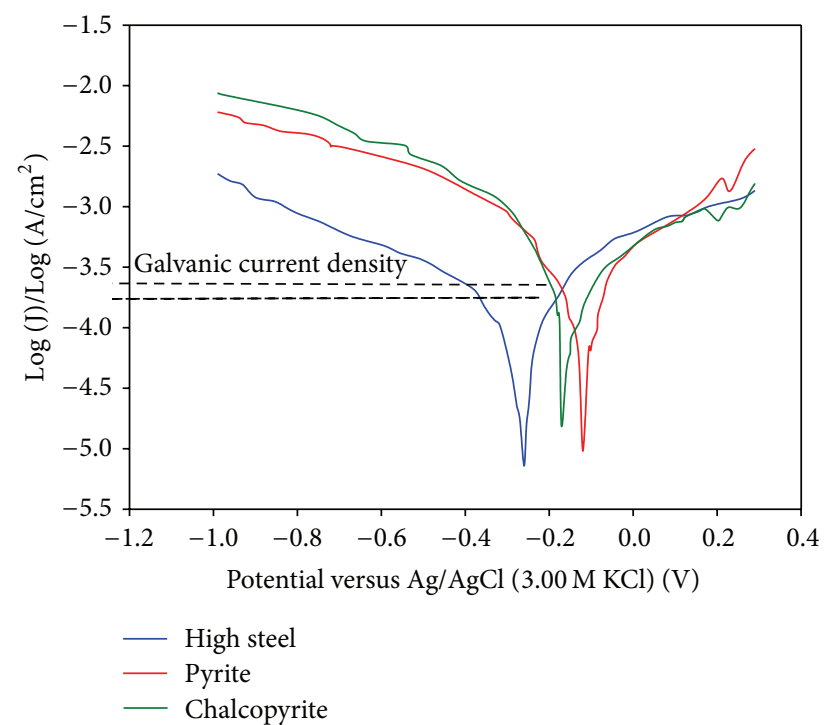

(c)

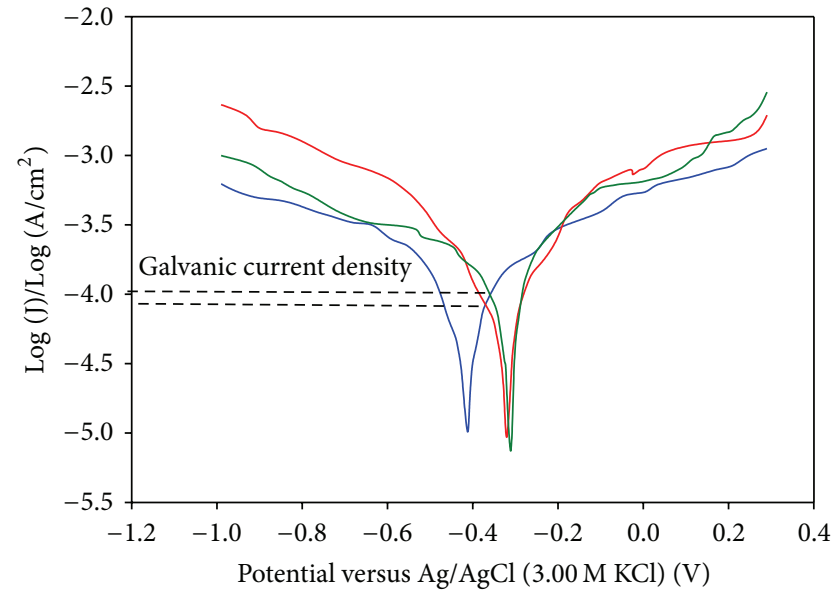

(b)

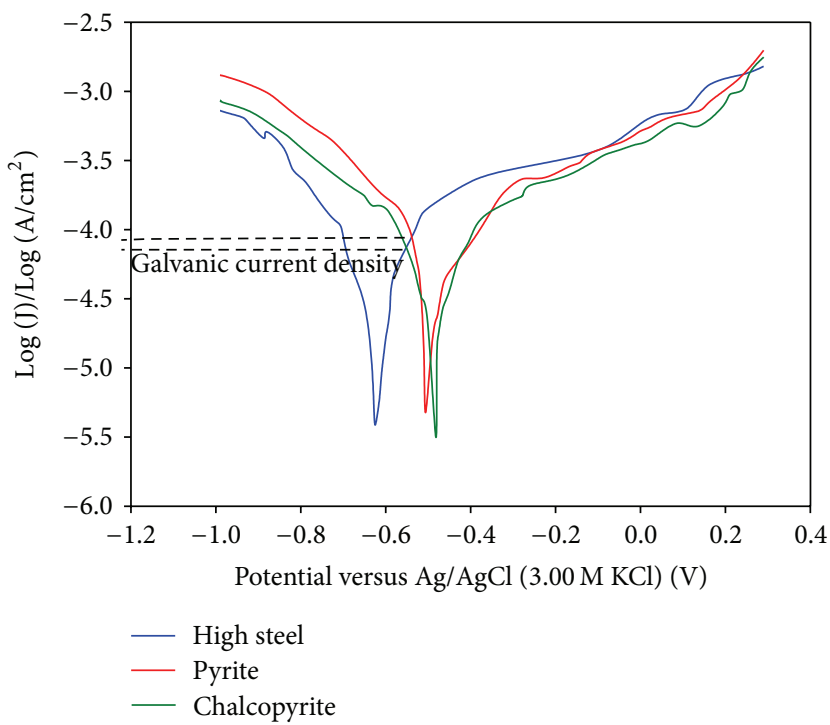

(d)

Figure 3: Potentiodynamic polarization sweep curves of grinding medium, pyrite, and chalcopyrite during grinding of ore with high carbon chrome steel ball under nitrogen (a), air (b), and oxygen atmosphere (c), and without aeration (d) at a sweep rate of $50 \mathrm{mV} / \mathrm{s}$.

contacted. Model of galvanic interaction occurring between a single sulphide mineral (pyrite or chalcopyrite) and grinding media is illustrated in Figure 4(a) based on mixed potential model [30]. Pozzo et al. (1990) [31] described an electrochemical model for a two-sulphide mineral/grinding medium system as shown in Figure 4(b). According to Pozzo et al. (1990), in grinding of the Sarcheshmeh sulphide ore composed of chalcopyrite, pyrite (as two main mineral) with low alloy or high carbon chromium steel ball, the noblest electrode (the highest rest potential) in the series is pyrite (see Table 4). Therefore, pyrite will act as cathode and the grinding media always as anode. The other sulphide mineral (chalcopyrite), with lower rest potential than pyrite but higher rest potential than the grinding medium, developed an intermediate anodic (Figure 4) depending on its rest potential.
Under the above conditions, the following electrochemical reactions may be occurred on sulphide minerals and grinding media surface $[22,32-34]$.

Cathodic reaction on cathodic mineral surface:

$$
\frac{1}{2} \mathrm{O}_{2}+\mathrm{H}_{2} \mathrm{O}+2 \mathrm{e}^{-} \longrightarrow 2 \mathrm{OH}^{-}
$$

Anodic reactions on medium surface:

$$
\begin{aligned}
& \mathrm{Fe} \longrightarrow \mathrm{Fe}^{2+}+2 \mathrm{e}^{-} \\
& \mathrm{Fe} \longrightarrow \mathrm{Fe}^{3+}+3 \mathrm{e}^{-}
\end{aligned}
$$


TABLE 3: The measured galvanic current densities $\left(\mu \mathrm{A} / \mathrm{cm}^{2}\right)$ and combination potentials $(\mathrm{mV})$ (versus $\mathrm{Ag} / \mathrm{AgCl}(3.0 \mathrm{M} \mathrm{KCl})$ ) of pyrite, chalcopyrite with low alloy and high carbon chromium steel ball under different aeration conditions in mill.

\begin{tabular}{|c|c|c|}
\hline Aeration conditions & $\begin{array}{l}\text { Galvanic current density of pyrite and } \\
\text { low alloy steel }\end{array}$ & $\begin{array}{l}\text { Combination potentials (potential } \\
\text { between pyrite and low steel ball) }\end{array}$ \\
\hline Without aeration & 109.63 & -345 \\
\hline Nitrogen & 63.41 & -538 \\
\hline Air & 111.97 & -203 \\
\hline Oxygen & 277.50 & -179 \\
\hline Aeration conditions & $\begin{array}{l}\text { Galvanic current density of chalcopyrite } \\
\text { and low alloy steel ball }\end{array}$ & $\begin{array}{c}\text { Combination potentials (potential } \\
\text { between chalcopyrite and low steel ball) }\end{array}$ \\
\hline Without aeration & 86.54 & -352 \\
\hline Nitrogen & 33.98 & -569 \\
\hline Air & 139.23 & -193 \\
\hline Oxygen & 271.26 & -189 \\
\hline Aeration conditions & $\begin{array}{l}\text { Galvanic current density of pyrite and } \\
\text { high carbon chromium steel ball }\end{array}$ & $\begin{array}{l}\text { Combination potentials (potential } \\
\text { between pyrite and high carbon } \\
\text { chromium steel ball) }\end{array}$ \\
\hline Without aeration & 86.53 & -531 \\
\hline Nitrogen & 26.33 & -535 \\
\hline Air & 89.98 & -372 \\
\hline Oxygen & 212.18 & -172 \\
\hline Aeration conditions & $\begin{array}{l}\text { Galvanic current density of chalcopyrite } \\
\text { and high carbon chromium steel ball }\end{array}$ & $\begin{array}{c}\text { Combination potentials (potential } \\
\text { between pyrite and high carbon } \\
\text { chromium steel ball) }\end{array}$ \\
\hline Without aeration & 71.48 & -552 \\
\hline Nitrogen & 15.73 & -556 \\
\hline Air & 101.27 & -362 \\
\hline Oxygen & 170.56 & -190 \\
\hline
\end{tabular}

TABLE 4: Rest potential of sulphide minerals and steel media at near neutral $\mathrm{pH}[7,32]$.

\begin{tabular}{|c|c|c|c|c|}
\hline \multirow{2}{*}{ Mineral } & \multirow{2}{*}{ Solution } & \multicolumn{3}{|c|}{ Rest potential versus SHE/mV } \\
\hline & & $\mathrm{N}_{2}$ & Air & $\mathrm{O}_{2}$ \\
\hline \multirow{2}{*}{ Galena } & Distilled water & 142 & 172 & 218 \\
\hline & $0.5 \mathrm{~mol} / \mathrm{L} \mathrm{NaCl}(\mathrm{pH}=10.5)$ & 45 & & 95 \\
\hline \multirow[t]{2}{*}{ Pyrite } & Distilled water & 405 & 445 & 485 \\
\hline & $0.001 \mathrm{~mol} / \mathrm{L} \mathrm{Na}_{2} \mathrm{SO}_{4}$ & 45 & & 95 \\
\hline Pyrrhotite & Distilled water & 125 & 262 & 295 \\
\hline \multirow[t]{2}{*}{ Arsenopyrite } & Distilled water & 277 & 303 & 323 \\
\hline & Distilled water & 190 & 355 & 371 \\
\hline \multirow[t]{2}{*}{ Chalcopyrite } & $0.05 \mathrm{~mol} / \mathrm{L} \mathrm{Na}_{2} \mathrm{SO}_{4}$ & 115 & & 265 \\
\hline & $0.5 \mathrm{~mol} / \mathrm{L} \mathrm{NaCl}(\mathrm{pH}=10.5)$ & 65 & & 115 \\
\hline Sphalerite & $0.5 \mathrm{~mol} / \mathrm{L} \mathrm{NaCl}(\mathrm{pH}=10.5)$ & 30 & & 60 \\
\hline \multirow[t]{2}{*}{ Mild steel } & Distilled water & -515 & -335 & -175 \\
\hline & $0.5 \mathrm{~mol} / \mathrm{L} \mathrm{NaCl}$ & -395 & & \\
\hline Ferronickel steel & $0.5 \mathrm{~mol} / \mathrm{L} \mathrm{NaCl} \mathrm{pH}=10.5$ & -255 & & -205 \\
\hline
\end{tabular}

Precipitation:

$$
\begin{gathered}
\mathrm{Fe}^{2+}+2 \mathrm{OH}^{-} \longrightarrow \mathrm{Fe}(\mathrm{OH})_{2} \\
\mathrm{Fe}(\mathrm{OH})_{2}+\mathrm{OH}^{-} \longleftrightarrow \mathrm{Fe}(\mathrm{OH})_{3}+\mathrm{e}^{-}
\end{gathered}
$$

Reaction on anodic mineral surface (two sulphide mineral and medium system),

$$
\mathrm{MS} \longleftrightarrow \mathrm{M}^{2+}+\mathrm{S}+2 \mathrm{e}^{-}
$$

As can be considered in above reactions, ferrous ions are released into the solution as a result of anodic oxidation of 


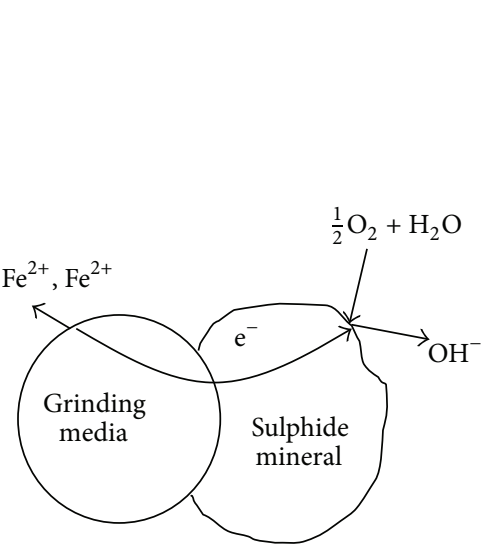

(a)

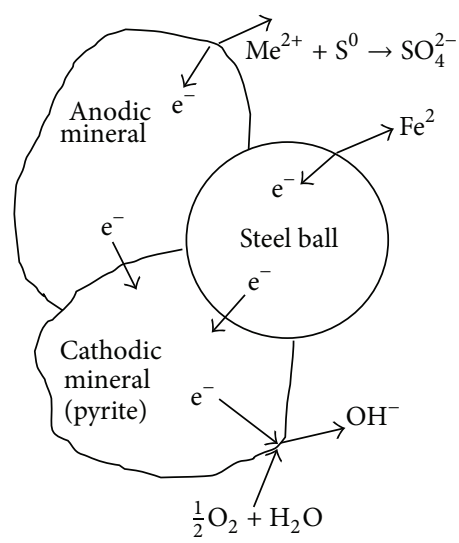

(b)

FIGURE 4: Model galvanic interactions between a single sulphide mineral (a) [31] and two sulphide minerals (b) [33] and steel ball during grinding.

grinding media simultaneously with the cathodic reduction of dissolved oxygen.

The flow of electrons from the grinding media to sulphide minerals increases the oxidation of grinding media [35], leading to more oxidized iron species in the slurry. In this work, the EDTA extraction technique was used as a measure of the corrosion of the system. It is not an accurate measure, but it gives general information on the process. The amount of oxidized iron species from minerals and/or grinding media in the mill discharge under different aeration conditions for low alloy and high carbon chrome steel balls were obtained by EDTA extraction technique as shown in Figure 5. It is observed that the grinding media, as well as the type of aeration influence the amount of EDTA extractable iron. It is seen that low alloy steel ball under oxygen atmosphere produces the highest amount of EDTA extractable iron in the slurry, whilst high carbon chromium steel ball under nitrogen atmosphere leads to the lowest amount.

\section{Conclusion}

The purpose of this study was to investigate the galvanic interaction between pyrite and chalcopyrite with low alloy and high carbon chromium steel balls in grinding of the Sarcheshmeh porphyry copper sulphide ore. A specialized laboratory grinding system, which linked to electrochemical equipment, was constructed to study the grinding environment electrochemistry and quantify the galvanic current between pyrite and chalcopyrite with grinding media. The major conclusions based on this research work can be summarized as follows.

(i) High carbon chromium steel ball under nitrogen gas has the lowest galvanic current and low alloy steel ball under oxygen gas had the highest galvanic current in mineral-grinding media system.

(ii) Grinding media was anodic relative to pyrite and chalcopyrite, and therefore the electrons flowed from the media to the minerals. Pyrite or chalcopyrite with

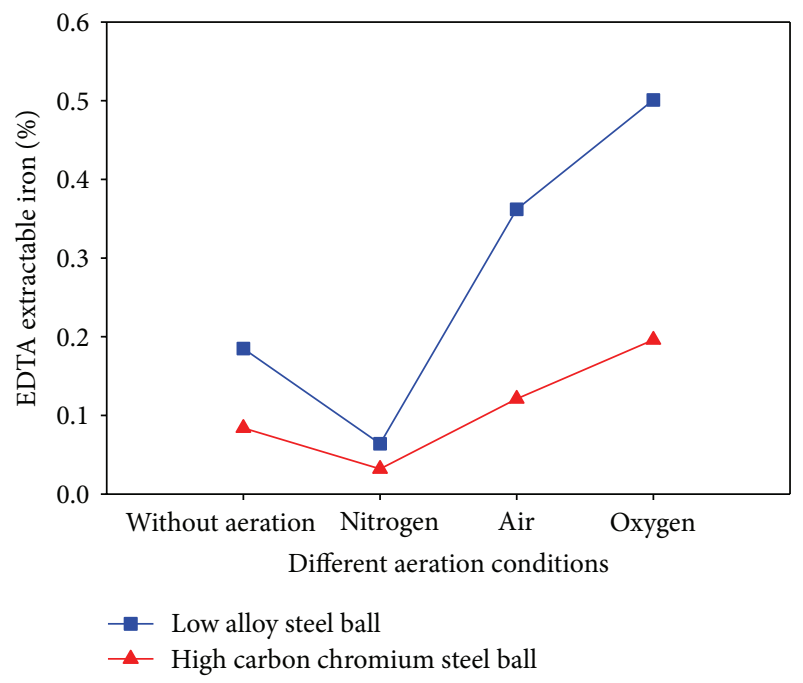

Figure 5: EDTA extractable iron in the mill discharge under different aeration conditions for two types of grinding media.

a higher rest potential acted as the cathode, whilst the grinding media with a lower rest potential acted as the anode, when they were electrochemically contacted in single mineral-media system.

(iii) In two sulphide minerals-media (pyrite/chalcopyrite/ media) systems, pyrite is the noblest electrode acted as cathode and the grinding media always as anode whilst chalcopyrite with lower rest potential than pyrite but higher rest potential than the medium developed an intermediate anodic depending on its rest potential.

(iv) Low alloy steel ball under oxygen produced the highest amount of EDTA extractable iron in the slurry, whilst high carbon chromium steel ball under nitrogen atmosphere produced the lowest amount. 
(v) Polarization curves for pyrite, chalcopyrite and medium (low alloy and high carbon chromium steel balls) were obtained by electrochemical equipment and using linear sweep voltammetry technique under different aeration conditions and without aeration. Approximately, in all of polarization curves of minerals and steel balls, the activity, passivity and transpassivity regions could be distinguished. The polarization plots for balls showed a small passivating region, which may be due to the iron hydroxide species, which passivates the steel ball surface and prevents further oxidation. In addition, limiting current value was also attained based on polarization plots.

\section{Acknowledgments}

This work was supported by Research and development division and funded by National Iranian Copper Industries Company. The authors wish to thank the manager and personnel of the Sarcheshmeh copper mine for their support during this research.

\section{References}

[1] C. J. Greet, "The significance of grinding environment on the flotation of UG2 ores," in Proceedings of the 3th International Platinum Conference, Platinum in Transformation, p. 29, The Southern African Institute of Mining and Metallurgy, Sun City, South Africa, 2008.

[2] W. J. Bruckard, G. J. Sparrow, and J. T. Woodcock, "A review of the effects of the grinding environment on the flotation of copper sulphides," International Journal of Mineral Processing, vol. 100, no. 1-2, pp. 1-13, 2011.

[3] M. Rey and V. Formanek, "Some factors affecting selectivity in the differential flotation of lead-zinc ores in the presence of oxidized lead mineral," in Proceedings of the 5th International Mineral Processing Congress, pp. 343-352, Institution of Mining and Metallurgy, London, UK, 1960.

[4] R. L. Pozzo and I. Iwasaki, "An electrochemical study of pyrrhotite-grinding media interaction under abrasive condition," Corrosion, vol. 43, no. 3, pp. 159-164, 1987.

[5] R. L. Pozzo and I. Iwasaki, "Pyrite-pyrrhotite grinding media interactions and their effects on media wear and flotation," Journal of the Electrochemical Society, vol. 136, no. 6, pp. 17341740, 1989.

[6] Y. Peng, S. Grano, D. Fornasiero, and J. Ralston, "Control of grinding conditions in the flotation of chalcopyrite and its separation from pyrite," International Journal of Mineral Processing, vol. 69, no. 1-4, pp. 87-100, 2003.

[7] Y. Peng, S. Grano, D. Fornasiero, and J. Ralston, "Control of grinding conditions in the flotation of galena and its separation from pyrite," International Journal of Mineral Processing, vol. 70, no. 1-4, pp. 67-82, 2003.

[8] G. Huang and S. Grano, "Galvanic interaction between grinding media and arsenopyrite and its effect on flotation: part I. Quantifying galvanic interaction during grinding," International Journal of Mineral Processing, vol. 78, no. 3, pp. 182-197, 2006.

[9] G. Huang and S. Grano, "Galvanic interaction of grinding media with pyrite and its effect on floatation," Minerals Engineering, vol. 18, no. 12, pp. 1152-1163, 2005.
[10] S. Grano, "The critical importance of the grinding environment on fine particle recovery in flotation," Minerals Engineering, vol. 22, no. 4, pp. 386-394, 2009.

[11] H. Majima and E. Peter, "Electrochemistry of sulphide dissolution in hydrometallurgical systems," in Proceedings of the international Mineral Processing Congress, p. 13, Leningrad, Russia, 1968.

[12] V. Vathsala and K. A. Natarajan, "Some electrochemical aspects of grinding media corrosion and sphalerite flotation," International Journal of Mineral Processing, vol. 26, no. 3-4, pp. 193-203, 1989.

[13] M. K. Yelloji Rao and K. A. Natarajan, "Effect of galvanic interaction between grinding media and minerals on sphalerite flotation," International Journal of Mineral Processing, vol. 27, no. 1-2, pp. 95-109, 1989.

[14] M. K. Yelloji Rao and K. A. Natarajan, "Effect of electrochemical interactions among sulfide minerals and grinding medium on chalcopyrite flotation," Minerals and Metallurgical Processing, vol. 6, no. 3, pp. 146-151, 1989.

[15] J. E. Dutrizac, R. J. C. Mac Donald, and T. R. Ingraham, "Effect of pyrite, chalcopyrite and digenite on rate of bornite dissolution in acidic ferric sulphate solutions," Canadian Metallurgical Quarterly, vol. 5, no. 1, pp. 3-7, 1971.

[16] J. E. Dutrizac and R. J. C. Mac Donald, "Effect of impurities on the rate of chalcopyrite dissolution," Canadian Metallurgical Quarterly, vol. 12, no. 4, pp. 409-420, 1973.

[17] H. G. Linge, "Reactivity comparison of Australian chalcopyrite concentrates in acidified ferric solution," Hydrometallurgy, vol. 2, no. 3, pp. 219-233, 1977.

[18] K. A. Natarajan, S. C. Riemer, and I. Iwasaki, "Corrosive and erosive wear in magnetite taconite grinding," Minerals and Metallurgical Processing, vol. 1, no. 1, pp. 10-14, 1984.

[19] R. L. Pozzo and I. Iwasaki, "Effect of pyrite and pryyhotite on the corrosive wear of grinding media," Minerals and Metallurgical Processing, vol. 4, no. 3, pp. 166-171, 1987.

[20] J. W. Jang, I. Iwasaki, and J. J. Moore, "Effect of galvanic interaction between martensite and ferrite grinding media wear," Corrosion, vol. 45, no. 5, pp. 402-407, 1989.

[21] M. K. Yelloji Rao and K. A. Natarajan, "Factors influencing ball wear and flotation with respect to ore grinding," Mineral Processing and Extractive Metallurgy Review, vol. 7, no. 3-4, pp. 137-173, 1991.

[22] K. A. Natarajan, "Laboratory studies on ball wear in the grinding of a chalcopyrite ore," International Journal of Mineral Processing, vol. 46, no. 3-4, pp. 205-213, 1996.

[23] J. H. Ahn and J. E. Gebhardt, "Effect of grinding mediachalcopyrite interaction on the self-induced flotation of chalcopyrite," International Journal of Mineral Processing, vol. 33, no. 1-4, pp. 243-262, 1991.

[24] K. A. Natarajan and I. Iwasaki, "Electrochemical aspects of grinding media-mineral interactions in magnetite ore grinding," International Journal of Mineral Processing, vol. 13, no. 1, pp. 53-71, 1984.

[25] C. J. Greet, G. L. Small, P. Steinier, and S. R. Grano, “The Magotteaux Mill: investigating the effect of grinding media on pulp chemistry and flotation performance," Minerals Engineering, vol. 17, no. 7-8, pp. 891-896, 2004.

[26] H. R. Barkhordari, E. Jorjani, A. Eslami, and M. Noaparast, "Occurrence mechanism of silicate and aluminosilicate minerals in Sarcheshmeh copper flotation concentrate," International Journal of Minerals, Metallurgy and Materials, vol. 16, no. 5, pp. 494-499, 2009. 
[27] J. A. Rumball and G. D. Richmond, "Measurement of oxidation in a base metal flotation circuit by selective leaching with EDTA," International Journal of Mineral Processing, vol. 48, no. 1-2, pp. 1-20, 1996.

[28] V. J. Cullinan, S. R. Grano, C. J. Greet, N. W. Johnson, and J. Ralston, "Investigating fine galena recovery problems in the lead circuit of Mount Isa Mines Lead/Zinc Concentrator part 1: grinding media effects," Minerals Engineering, vol. 12, no. 2, pp. 147-163, 1999.

[29] C. Greet and R. S. C. Smart, "Diagnostic leaching of galena and its oxidation products with EDTA," Minerals Engineering, vol. 15, no. 7, pp. 515-522, 2002.

[30] Y. Peng and S. Grano, "Inferring the distribution of iron oxidation species on mineral surfaces during grinding of base metal sulphides," Electrochimica Acta, vol. 55, no. 19, pp. 54705477, 2010.

[31] R. L. Pozzo, A. S. Malicsi, and I. Iwasaki, "Pyrite-pyrrhotitegrinding media contact and its effect on flotation," Minerals and Metallurgical Processing, vol. 7, no. 1, pp. 16-21, 1990.

[32] J. J. Pavlica and I. Iwasaki, "Electrochemical and magnetic interaction in pyrrhotite flotation," SME-AIME Transactions, vol. 272, pp. 1885-1890, 1982.

[33] X. Cheng and I. Iwasaki, "Pulp potential and its implications to sulphide flotation," Mineral Processing and Extractive Metallurgy Review, vol. 11, no. 4, pp. 187-210, 1992.

[34] K. A. Natarajan, S. C. Riemer, and I. Iwasaki, "Influence of pyrrhotite on the corrosive wear of grinding balls in magnetite ore grinding," International Journal of Mineral Processing, vol. 13, no. 1, pp. 73-81, 1984.

[35] C. J. Martin, R. E. McIvor, J. A. Finch, and S. R. Rao, "Review of the effect of grinding media on flotation of sulphide minerals," Minerals Engineering, vol. 4, no. 2, pp. 121-132, 1991. 

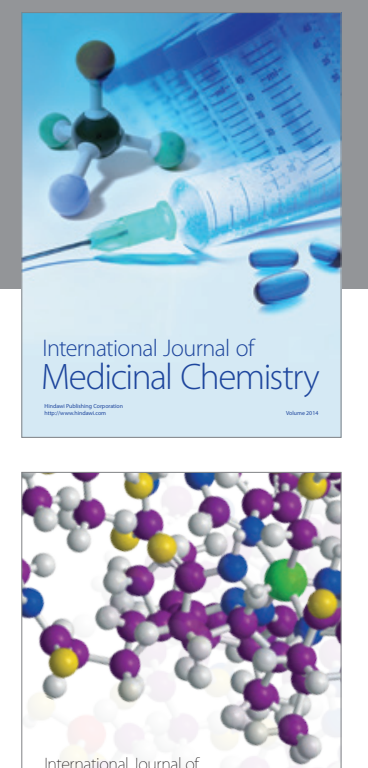

\section{Carbohydrate} Chemistry

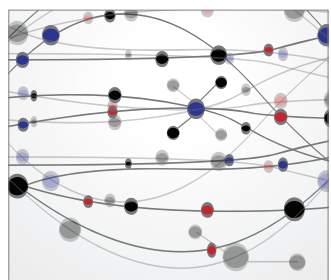

The Scientific World Journal
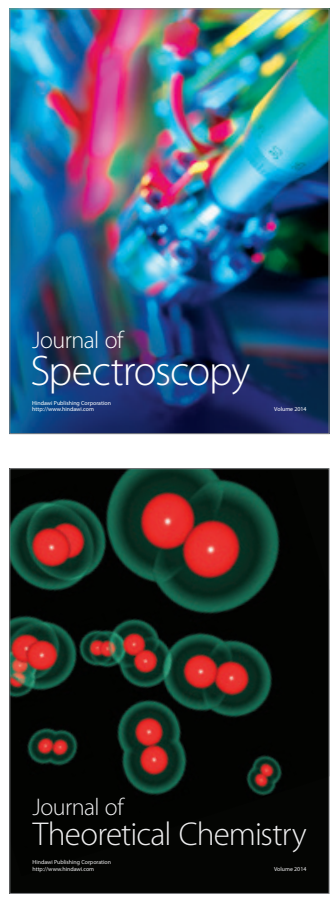
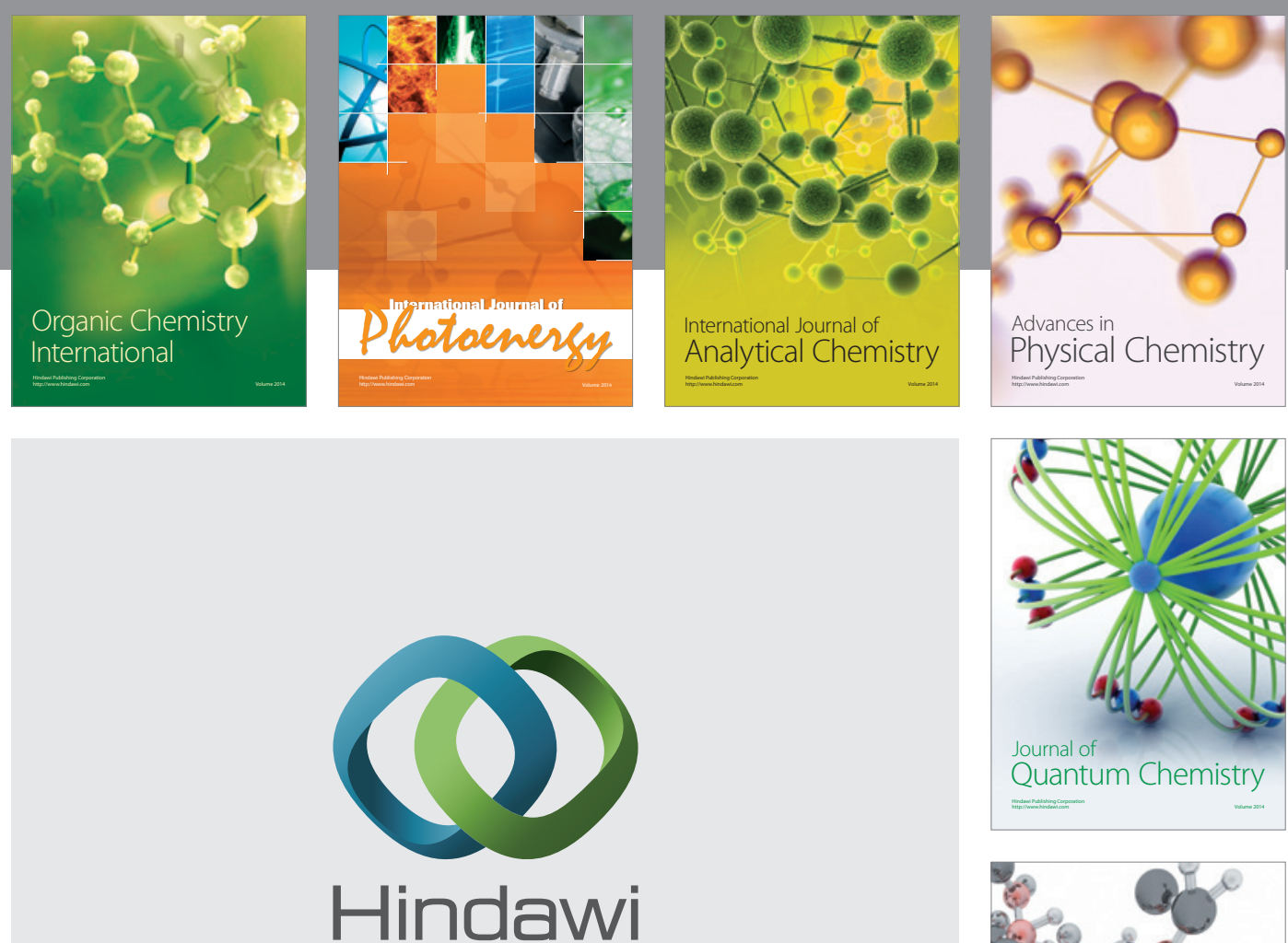

Submit your manuscripts at

http://www.hindawi.com

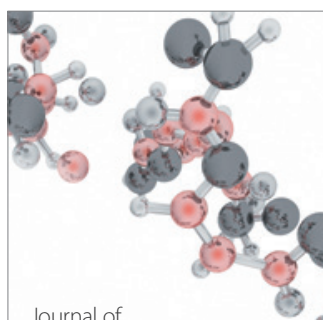

Analytical Methods

in Chemistry

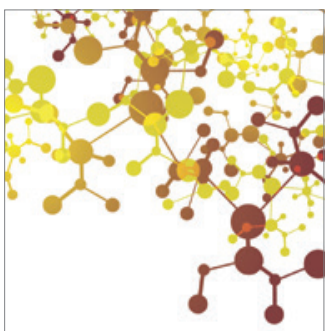

Journal of

Applied Chemistry

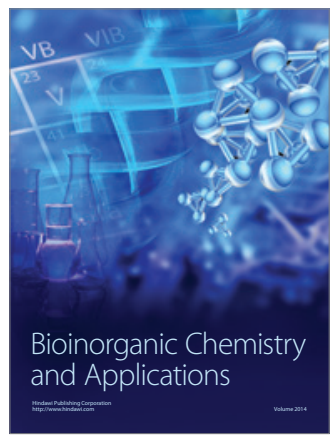

Inorganic Chemistry
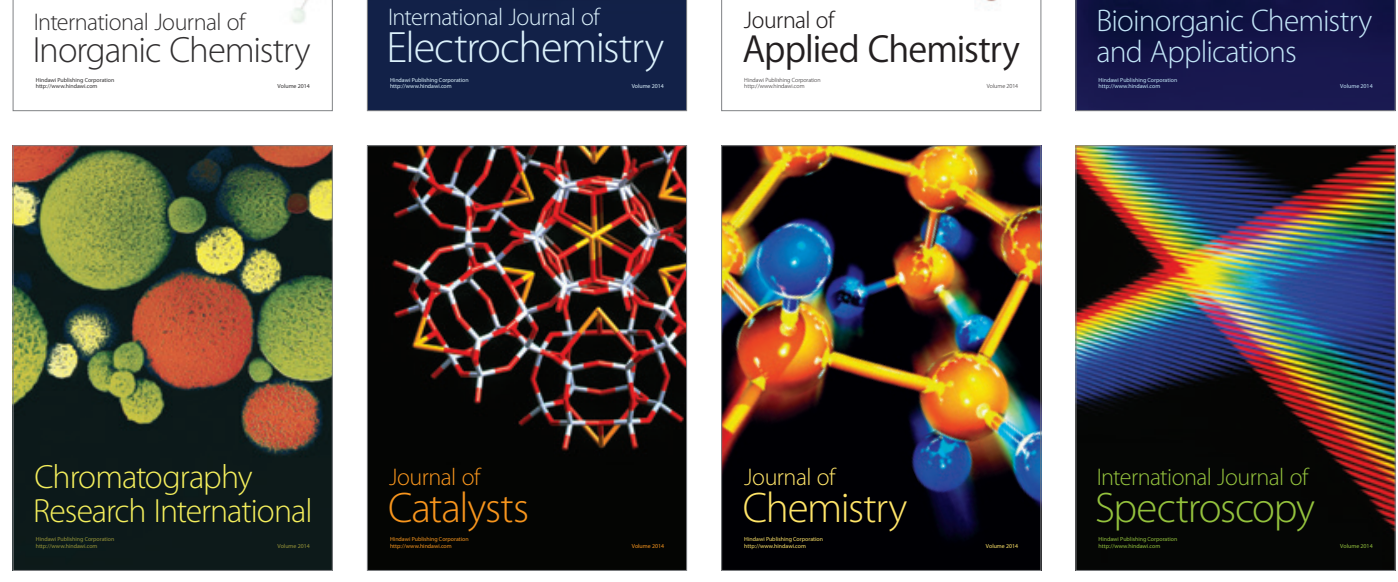